\title{
Transmission beam pattern and dynamics of a spinner dolphin (Stenella longirostris)
}

Adam B. Smith, Aude F. Pacini, Paul E. Nachtigall, Gail E. Laule, Lemnuel V. Aragones, Carlo Magno, and Leo J. A. Suarez

Citation: The Journal of the Acoustical Society of America 145, 3595 (2019); doi: 10.1121/1.5111347

View online: https://doi.org/10.1121/1.5111347

View Table of Contents: https://asa.scitation.org/toc/jas/145/6

Published by the Acoustical Society of America

\section{ARTICLES YOU MAY BE INTERESTED IN}

Song production by the North Pacific right whale, Eubalaena japonica

The Journal of the Acoustical Society of America 145, 3467 (2019); https://doi.org/10.1121/1.5111338

50 to $30-\mathrm{Hz}$ triplet and singlet down sweep vocalizations produced by sei whales (Balaenoptera borealis) in the western North Atlantic Ocean

The Journal of the Acoustical Society of America 145, 3351 (2019); https://doi.org/10.1121/1.5110713

Porpoise click classifier (PorCC): A high-accuracy classifier to study harbour porpoises (Phocoena phocoena) in the wild

The Journal of the Acoustical Society of America 145, 3427 (2019); https://doi.org/10.1121/1.5110908

Echolocation signals of free-ranging pantropical spotted dolphins (Stenella attenuata) in the South China Sea

The Journal of the Acoustical Society of America 145, 3480 (2019); https://doi.org/10.1121/1.5111742

Position of an acoustic window in a beluga whale: Computation based on auditory evoked potential latencies

The Journal of the Acoustical Society of America 145, 3578 (2019); https://doi.org/10.1121/1.5111752

Click characteristics of northern bottlenose whales (Hyperoodon ampullatus) and Sowerby's beaked whales (Mesoplodon bidens) off eastern Canada

The Journal of the Acoustical Society of America 146, 307 (2019); https://doi.org/10.1121/1.5111336 


\title{
Transmission beam pattern and dynamics of a spinner dolphin (Stenella longirostris)
}

\author{
Adam B. Smith, ${ }^{\text {a) }}$ Aude F. Pacini, and Paul E. Nachtigall \\ Marine Mammal Research Program, Hawaii Institute of Marine Biology, University of Hawaii at Manoa, \\ Kaneohe, Hawaii 96744, USA \\ Gail E. Laule \\ Ocean Adventure, Camayan Wharf, West Ilanin Forest, Subic Bay Freeport Zone, Philippines \\ Lemnuel V. Aragones \\ Institute of Environmental Science and Meteorology, University of the Philippines, Diliman, Quezon City, \\ Philippines \\ Carlo Magno and Leo J. A. Suarez \\ Ocean Adventure, Camayan Wharf, West Ilanin Forest, Subic Bay Freeport Zone, Philippines
}

(Received 14 January 2019; revised 16 May 2019; accepted 24 May 2019; published online 19 June 2019)

Toothed whales possess a sophisticated biosonar system by which ultrasonic clicks are projected in a highly directional transmission beam. Beam directivity is an important biosonar characteristic that reduces acoustic clutter and increases the acoustic detection range. This study measured click characteristics and the transmission beam pattern from a small odontocete, the spinner dolphin (Stenella longirostis). A formerly stranded individual was rehabilitated and trained to station underwater in front of a 16-element hydrophone array. On-axis clicks showed a mean duration of 20.1 $\mu \mathrm{s}$, with mean peak and centroid frequencies of 58 and $64 \mathrm{kHz}$ [standard deviation (s.d.) \pm 30 and $\pm 12 \mathrm{kHz}$ ], respectively. Clicks were projected in an oval, vertically compressed beam, with mean vertical and horizontal beamwidths of $14.5^{\circ}$ (s.d. \pm 3.9 ) and $16.3^{\circ}$ (s.d. \pm 4.6 ), respectively. Directivity indices ranged from 14.9 to $27.4 \mathrm{~dB}$, with a mean of $21.7 \mathrm{~dB}$, although this likely represents a broader beam than what is normally produced by wild individuals. A click subset with characteristics more similar to those described for wild individuals exhibited a mean directivity index of $23.3 \mathrm{~dB}$. Although one of the broadest transmission beams described for a dolphin, it is similar to other small bodied odontocetes. (C) 2019 Acoustical Society of America.

https://doi.org/10.1121/1.5111347

[LNK]

Pages: 3595-3605

\section{INTRODUCTION}

Echolocation evolved in odontocetes as their primary means for foraging, allowing them to detect and localize objects in their environment by producing and receiving acoustic signals (Au, 1993). The ability to acoustically determine the location of a target is due, in part, to the directivity of the outgoing biosonar signal. High signal directivity reduces acoustic clutter from peripheral objects, increases the source level of the projected signal, and increases the detection range of a biosonar system (Urick, 1983). Therefore, the directivity patterns of echolocation signals as they are transmitted into the environment are an important characteristic for understanding odontocete acoustic biology.

Beam shapes and directivity measurements have been described from 19 odontocete species across seven families (see supplementary material of Jensen et al., 2018). These studies have increased our understanding of the selection pressures that have shaped this system and the acoustic

\footnotetext{
a) Present address: Woods Hole Oceanographic Institution, 266 Woods Hole Road, Woods Hole, MA 02543-1050, USA. Electronic mail: absmith@whoi.edu
}

strategies utilized to search for, and acquire, prey. The directivity of a projected sound beam is influenced by a number of factors, which include the frequency content of the projected signal as well as the size and shape of the structures generating and transmitting the signal (Urick, 1983). Higher frequency signals are projected in a narrower beam than lower frequency signals for a transducer of the same size. Likewise, the same signal projected from a larger transducer will be more directional than if it were projected from a smaller one. In conjunction with changes in click source characteristics, odontocetes have the ability to adapt the directivity of their outgoing beam in relation to the distance to a target; as the distance to a target is reduced, the beam is broadened (Jensen et al., 2015; Ladegaard et al., 2017; Wisniewska et al., 2015). The ensonification of a larger area at close range decreases the likelihood of prey escaping perpendicular to the animal's direction of approach by falling outside the acoustic field of view (Wisniewska et al., 2015). Comparison between species indicates that some odontocetes utilize different click source characteristics that are adapted to suit specific environments (i.e., shallow, acoustically complex rivers versus the deep, open ocean), yet maintain a comparable beam directivity (Jensen et al., 2013; 
Ladegaard et al., 2015; Smith et al., 2016). Therefore, it is notable that despite the wide range of body sizes and click spectral characteristics across the suborder, beam directivity is similarly high and comparable in all odontocete species studied to date. Such similarity in transmission beam directivity has led to the hypothesis in both echolocating bats and odontocetes that there has been an evolutionary driving force in these animals to maintain a similarly high beam directivity throughout the diversity of species (Jakobsen et al., 2012; Jensen et al., 2018; Koblitz et al., 2012).

Many of the smaller odontocetes for which transmission beam data is available produce narrow-band high frequency echolocation clicks with very high frequency content, which results in an increased beam directivity within the transmission system. While the evolution of such click production may have been driven by avoidance of predation by killer whales (Morisaka and Connor, 2007), it may also may help compensate for the reduced beam directivity that comes with a smaller body size and thus a smaller sound generating aperture (Koblitz et al., 2012). There are some similarly small-sized odontocetes that produce broad-band high frequency (BBHF) echolocation clicks with dominant spectral emphasis from a half to one octave lower in frequency. Thus, such species lack the potential compensation in beam directivity that would come from producing narrow-band high frequency clicks and would provide a valuable point for comparison.

In the current study, we describe the transmission beam of a spinner dolphin (Stenella longirostris) by recording echolocation clicks from a previously stranded and rehabilitated captive individual using a 16-element hydrophone array. Spinner dolphins are small-bodied delphinids that live in both coastal and pelagic subtropical waters of the Atlantic, Pacific, and Indian Oceans. The species uses broadband echolocation signals to forage for small mesopelagic prey including fish, shrimp, and squid (Dolar et al., 2003; Lammers et al., 2004; Norris and Dohl, 1980; Perrin, 2009; Schotten et al., 2004). Sexually mature adults weigh $23-80 \mathrm{~kg}$ and measure $1.3-2.4 \mathrm{~m}$ in length (Perrin, 2009), making it one of the smallest odontocetes to produce BBHF clicks.

\section{MATERIALS AND METHODS}

\section{A. Experimental subject}

Echolocation clicks were recorded in October 2015, from an adult female spinner dolphin housed in the ocean pen complex at Ocean Adventure, a marine park in Subic Bay, Philippines. The dolphin had previously stranded near Badoc municipality on the west coast of Ilocos Norte province. The animal was initially treated on-site for two weeks before being transferred to Ocean Adventure for additional treatment and rehabilitation. The animal weighed $38.5 \mathrm{~kg}$ and was $1.7 \mathrm{~m}$ in length upon arrival at Ocean Adventures, and was treated with antibiotics, B-complex, vitamin E, liver support, and water for hydration. No ototoxic drugs were administered. An audiogram of this individual was previous published, indicating it had sensitive hearing from 16 to $90 \mathrm{kHz}$ with possible indications of some degree of high frequency hearing loss, which may have been due to acoustic trauma from an anthropogenic sound source such as dynamite fishing (Pacini et al., 2016).

\section{B. Data acquisition}

Click signals were recorded using an array of 16 Reson 4013 hydrophones (Reson, Slangerup, Denmark) attached to a polyvinyl chloride (PVC) frame and arranged in a star shaped pattern (Fig. 1). The frame consisted of eight arms that extended out from a central location with a signal hydrophone. Seven of the arms were identical and contained two hydrophones that were equally spaced $34 \mathrm{~cm}$ apart, while the eighth arm was shorter and contained only a single hydrophone spaced $52 \mathrm{~cm}$ from the central hydrophone. This arrangement resulted in an "outer" and "inner" ring of hydrophones. This configuration has successfully been utilized to investigate echolocation characteristics in a number of previous studies (e.g., Ibsen et al., 2012; Kloepper et al., 2012; Smith et al., 2016). Each hydrophone occupied an independent channel and was amplified by $20 \mathrm{~dB}$ with a custom-built 16 channel amplifier before being sent to two National Instruments DAQmx PCI6133 analog to digital (A/D) boards (National Instruments, Austin, TX). Signals were continuously recorded from all channels at a rate of $400 \mathrm{kHz}$ with a custom-written LabView program (National Instruments, Austin, TX) and saved on a laptop computer for offline analysis. The hydrophones were calibrated prior to the experiments and demonstrated less than $2 \mathrm{~dB}$ variation in sensitivity to received synthetic broadband click signals with a center frequency of $60 \mathrm{kHz}$ projected with a Reson 4040 (Reson, Slangerup, Denmark) transducer.

\section{Experimental setup and procedure}

Data were collected in one of the five connected floating ocean pens that constituted the rehabilitation enclosure at Ocean Adventure (Fig. 2). The experimental pen measured

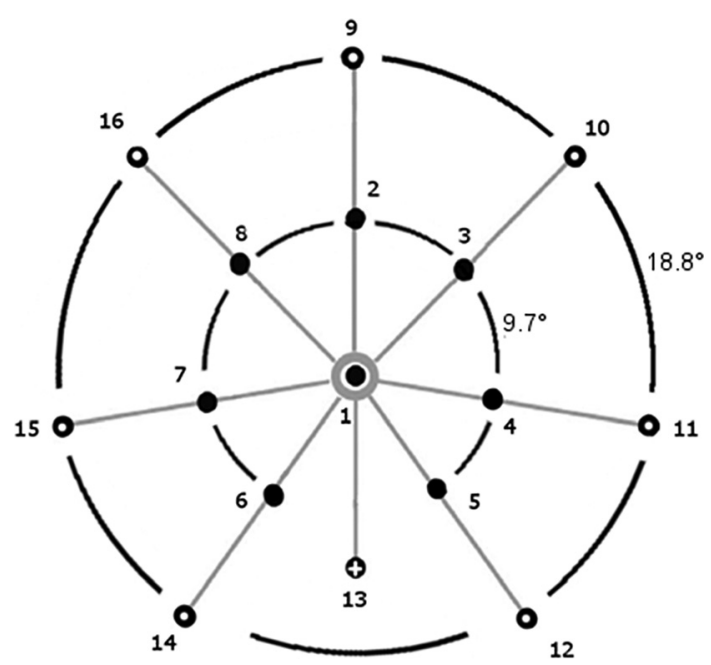

FIG. 1. Diagram of the hydrophone array used to record echolocation clicks. Sixteen elements (numbered) were arranged across eight PVC arms of the array (grey lines), resulting in an inner (solid circles), and outer (open circles) ring of hydrophones that were angular widths of 9.7 and 18.8 degrees from the center hydrophone. The eighth arm of the array contained a single hydrophone $(+)$ at an angular width of 14.6 degrees from the center hydrophone. Angular distances were calculated with the sound source at a distance of $2 \mathrm{~m}$ in front of the central hydrophone. 


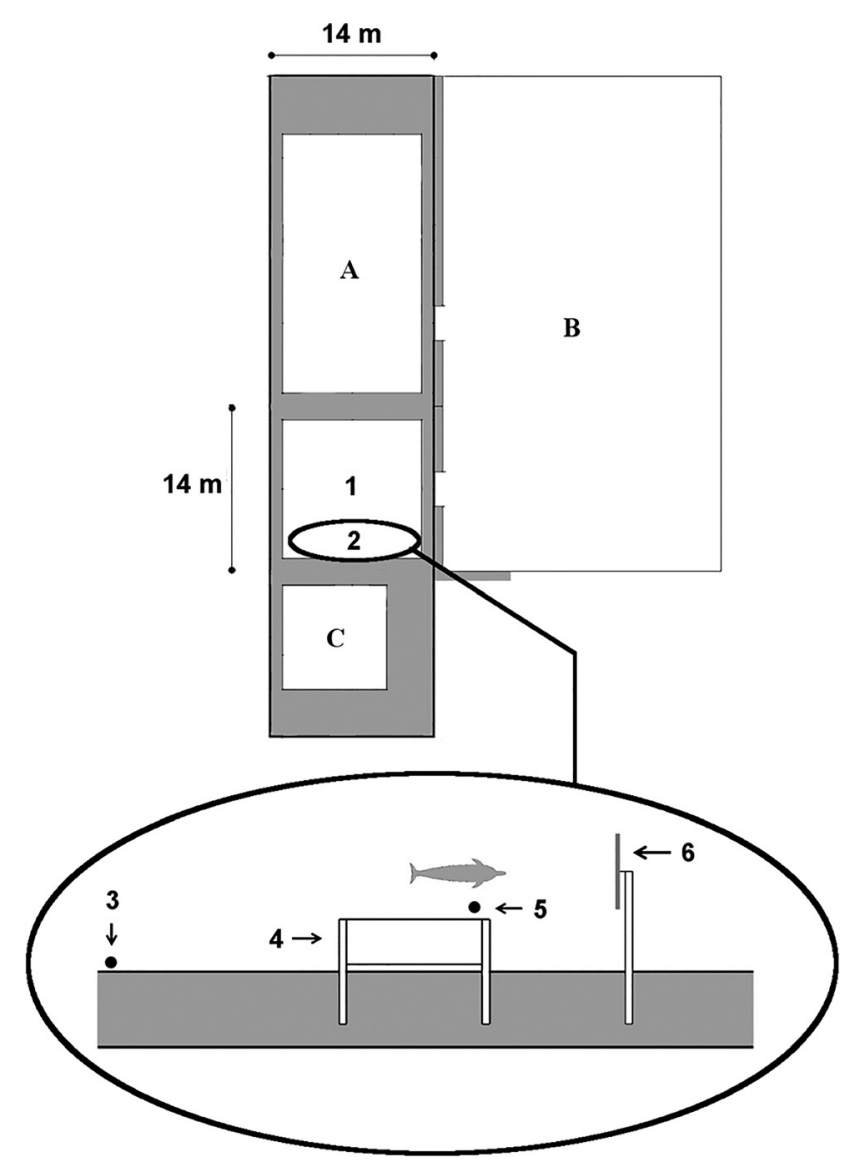

FIG. 2. Diagram of the rehabilitation pen complex and the experimental setup. (1) Experimental pen; (2) testing area; (3) pre-trial stationing location; (4) submerged metal shelf; (5) position of stabilizing trainer; (6) hydrophone array. Additional stranded and rescued odontocetes were located in adjacent pens, including Stenella attenuata (A, one individual), Steno bredanensis (B, three individuals), and Stenella longirostris (C, one individual).

$14 \times 14 \times 6 \mathrm{~m}(l \times w \times d)$. Prior to the start of an experimental session, the spinner dolphin was gated into the experiment pen to separate it from other dolphins that had also stranded and undergone rehabilitation, which included three rough-toothed dolphins (Steno bredanensis), a second spinner dolphin, and a pantropical spotted dolphin (Stenella attenuata). These other dolphins were held in consistent pen locations across the data collection sessions (see Fig. 2). The hydrophone array was suspended in the water via a wooden plank that extended perpendicular from the side of the pen deck above the water. The center hydrophone of the array was positioned at a depth of $1 \mathrm{~m}$ below the water surface. Data was collected while the animal stationed horizontally in the water at a depth of $1 \mathrm{~m}$ at a distance of $2 \mathrm{~m}$ in front of the array. The animal was trained to station still in the water while being supported and steadied by the arms of a trainer. To initiate a trial, a trainer at the surface would give the dolphin a cue to swim across the pen to a second trainer. At the same time as the cue, the second trainer would submerge at the stationing location on a breath-hold. The dolphin would station still horizontally in water using the submerged trainer's arms as a stationing platform. Near the stationing location, a metal shelf was submerged in the water from the pen deck with the horizontal plane of the shelf at a depth of $1 \mathrm{~m}$. The front edge of the shelf was located $2 \mathrm{~m}$ in front of the array. This shelf allowed the submerged trainer to maintain a consistent position in the water and also make small corrections to the dolphin's stationing location and orientation. By aligning the dolphin's blowhole with the leading edge and depth of the stationing shelf, a generally consistent depth and distance was maintained between the animal's blowhole and the center array hydrophone during data collection. An individual trial lasted between 15 and $45 \mathrm{~s}$, after which the stationing trainer would bridge the dolphin to return to the surface to receive a fish reward. An experimental session consisted of between 5 and 15 stationing trials.

\section{Data analysis}

The recordings were analyzed using custom algorithms written with MATLAB software (MathWorks Inc., Natick, MA). For each experiment session, a basic click detector was run on the data recording of the central array hydrophone and used to extract concurrent 500 sample windows from each hydrophone for every detection. These initial detections potentially included snapping shrimp sounds or clicks from dolphins in the adjacent pens. Analysis of the time of arrival differences for signals on each hydrophone was used to exclude all signals that did not originate from directly in front of the array. Given the arrangement of the pen complex, it was possible that signals generated from the rough-toothed dolphins in an adjacent pen (see Fig. 2) on the opposite side of the array could be recorded with the same incident angle as the spinner dolphin's signals. However, the three rough-toothed dolphins held in that pen exhibited acute hearing loss (Pacini et al., 2016) and were considered mute as no acoustic signals had been heard or recorded with these animals. Therefore, all signals that originated from a location perpendicular to the plane of the array hydrophones could be attributed to the study subject. The click detections were also visually examined to remove any detections that also contained low level acoustic artifacts that temporally overlapped with the click or were within the 500-sample detection window.

From the resulting dataset of spinner dolphin clicks, received levels were determined from the peak-to-peak (pp), root mean squared (rms), and energy flux density (EFD) voltage values of the signal recorded on each hydrophone. To determine the value of click parameters, first the on-axis signal was identified as the hydrophone with the highest pp voltage value. Signals in which the on-axis click was located on the outermost array hydrophones were omitted from further analysis. For each on-axis click, measurements were made of the pp, rms, and EFD source level (SL) as well as the duration $\left(\tau_{-10 \mathrm{~dB}}\right)$, which was calculated from the $-10 \mathrm{~dB}$ energy content of the spectral envelope. Spectral parameters such as centroid frequency $\left(f_{0}\right)$, peak frequency $\left(f_{\mathrm{p}}\right)$, rms bandwidth $\left(\mathrm{BW}_{\mathrm{rms}}\right),-3 \mathrm{~dB}$ bandwidth $\left(\mathrm{BW}_{-3 \mathrm{~dB}}\right)$, and $-10 \mathrm{~dB}$ bandwidth $\left(\mathrm{BW}_{-10 \mathrm{~dB}}\right)$ were calculated from a $256 \mathrm{pt}$ fast Fourier transform of the signal (Au, 1993).

The duration, peak and centroid frequencies, and spectral bandwidths were also compared between the on- and off-axis signals using a subset of the recordings where the on-axis signal was recorded on the center hydrophone. This ensured that the click parameters could be compared at 
consistent azimuths and elevations relative to the center of the transmission beam.

For statistical comparison, click recordings were grouped according to their angular width from the central hydrophone. The dolphin-array distance of $2 \mathrm{~m}$ resulted in the inner and outer rings of hydrophones each being positioned at an angular width of $9.7^{\circ}$ and $18.8^{\circ}$, resulting in three comparison groups $\left(0^{\circ}, 9.7^{\circ}\right.$, and $\left.18.8^{\circ}\right)$. The single hydrophone on the eighth array arm (angular width of $14.6^{\circ}$ ) was not included in the statistical comparison. We tested the null hypothesis of no difference in mean values between the three hydrophone groupings using the standard three-sample $F$-statistic. However, to account for both non-normality in the parameter distributions and the fact that mean values of each grouping were calculated from the same set of emitted clicks, we assessed the significance of the observed value of the $F$ statistic by the following randomization procedure (Manly, 2006). A new data set was constructed by randomizing the values calculated for each click separately. The three-sample $F$ statistic was calculated for this randomized data set. The procedure was repeated 1000 times and the observed significance level (or $p$-value) was approximated by the proportion of randomized data sets for which the $F$ statistic exceeded the observed value. Post hoc comparisons between pairs of angles were conducted using the two-sample analogue of this procedure.

To describe the transmission beam shape, the received levels of individual clicks on each hydrophone were interpolated over the nodes of a grid $(1 \mathrm{~cm}$ node spacing) superimposed over the shape of the array. A contour was then constructed representing $3 \mathrm{~dB}$ less than the peak sound pressure level (SPL) of the click, and the area of the contour was calculated to yield the $-3 \mathrm{~dB}$ beam area (Kloepper et al., 2012a; Smith et al., 2016). The height and width of the beam area were then used to calculate the horizontal and vertical angular beam widths. Using the angular beam widths, the directivity index was also calculated, as a measure of the directivity of a signal that is proportional to the size of the sound generating transducer. The directivity index of odontocete beams has been modeled and compared to the directional characteristics of a circular piston (Au, 1993) or conventional planar transducer (Au et al., 1995). In this study, we modeled the directivity index (DI) of the spinner dolphin transmission beam after a conventional planar transducer [Eq. (1) from Au and Hastings, 2008, p. 84]

$$
D I=10 \log _{10}\left(\frac{4 \pi A}{\lambda^{2}}\right),
$$

where $(\lambda)$ is the wavelength of the click centroid frequency, and $(A)$ is the area of the rectangular aperture. The rectangular aperture area was calculated by using the vertical and horizontal angular beam widths $(2 \theta)$ to determine the lengths $(L)$ of a thin vertical and horizontal cylindrical transducer [Eq. (2) derived from Au and Hastings, 2008, p. 65]

$$
L=\frac{0.443 \lambda}{\sin \theta} .
$$

The use of a conventional planar transducer model was the result of preliminary analysis of a subset of recorded clicks, which showed statistically significant differences between the horizontal and vertical angular beam widths (described in the results).

Cubic interpolation was also used to investigate potential frequency dependent characteristics of the transmission beam shape. Amplitude values from each hydrophone were averaged across $10-\mathrm{kHz}$ bands (up to $160 \mathrm{kHz}$ ), normalized to the peak amplitudes across all frequencies, and then interpolated at the nodes of the same $1 \mathrm{~cm}$ grid. The normalized amplitude values were plotted on a two-dimensional representation of the array. These plots were visually inspected for the presence of frequency-dependent single or dual lobed beam shapes, which have been documented in three other odontocete species (Kloepper et al., 2012b; Smith et al., 2016; Starkhammar et al., 2011).

\section{RESULTS}

A total of 12404 clicks were recorded across four experimental sessions. Of those, 1369 echolocation clicks met the criteria for inclusion in the analysis. Waveforms and spectra of a single click as recorded on all 16 array hydrophones can be seen in Figs. 3 and 4. On-axis clicks showed a mean $-10 \mathrm{~dB}$ envelope duration of $20.1 \mu$ s [standard deviation (s.d.) \pm 4.8 ]. The inter-click-interval of subsequent clicks within the various recorded click trains ranged from 1.9 to $302 \mathrm{~ms}$, with a mean of $18.6 \mathrm{~ms}$. Mean click source levels were $180 \mathrm{~dB}_{\mathrm{pp}}$ re: $1 \mu \mathrm{Pa}$ (s.d. \pm 9.1$), 170 \mathrm{~dB}_{\mathrm{rms}}$ re: $1 \mu \mathrm{Pa}$ (s.d. \pm 9.3 ), and $123 \mathrm{~dB}_{\text {efd }}$ re: $1 \mu \mathrm{Pa}^{2} *_{\mathrm{s}}$ (s.d. \pm 8.3 ). Click peak and centroid frequencies showed means of 57.9 and $65.1 \mathrm{kHz}$ (s.d. \pm 22.5 and $\pm 11.1 \mathrm{kHz}$ ), respectively. Centroid frequencies increased with increasing source level (linear regression, $R^{2}=0.16, p<0.05$ ). Mean rms, $-3 \mathrm{~dB}$, and $-10 \mathrm{~dB}$ bandwidths were $29.3 \mathrm{kHz}$ (s.d. \pm 5.7$), 54.4 \mathrm{kHz}$ (s.d. $\pm 20 \mathrm{kHz}$ ), and $107 \mathrm{kHz}$ (s.d. \pm 28 ), respectively. The mean quality factor, or $Q$, of the on-axis clicks was 2.3 (s.d. \pm 0.5 ). Table I summarizes all on-axis signal characteristics, as well as parameters described from wild spinner dolphins for comparison.

The $-3 \mathrm{~dB}$ beam shape was oval [Fig. 5(A)] and projected in a single lobe, with a mean beam area of $0.23 \mathrm{~m}^{2}$ (s.d. \pm 0.13$)$. Mean vertical and horizontal angular beam widths were $14.5^{\circ}$ (s.d. \pm 3.9 ) and $16.3^{\circ}$ (s.d. \pm 4.6 ), respectively. When separated into $10 \mathrm{kHz}$ bandwidths from 10 to $160 \mathrm{kHz}$, the frequency-dependent beam shape was also consistently single lobed [Fig. 5(B)]. There were no occurrences of dual-lobed beams within any clicks at any frequency range. Although the angular beamwidths varied from click to click, there was a significant difference between the vertical and horizontal angular beam widths [paired $t$-test, $p<0.001$, degrees of freedom $($ d.f. $)=1367$ ], indicating the transmission beam generally exhibited a small degree of dorso-ventral compression. In a few extreme cases, some clicks exhibited horizontal beam widths that were almost twice the vertical beam width [Fig. $5(\mathrm{C})$ ]. The directivity index of all clicks was calculated by modeling the sound generator as a rectangular transducer with a mean width and height of $7.8 \mathrm{~cm}$ (s.d. \pm 1.6 ) and $8.7 \mathrm{~cm}$ (s.d. \pm 1.5$)$, respectively. This resulted in DI values that ranged between 15 and $27.4 \mathrm{~dB}$, with a mean of $21.7 \mathrm{~dB}$ (s.d. \pm 2.1 ). Measurements of beam directivity (DI, BW $\mathrm{H}_{\mathrm{H}}$, and $\mathrm{BW}_{\mathrm{V}}$ ) showed strong linear relationships to both click source 


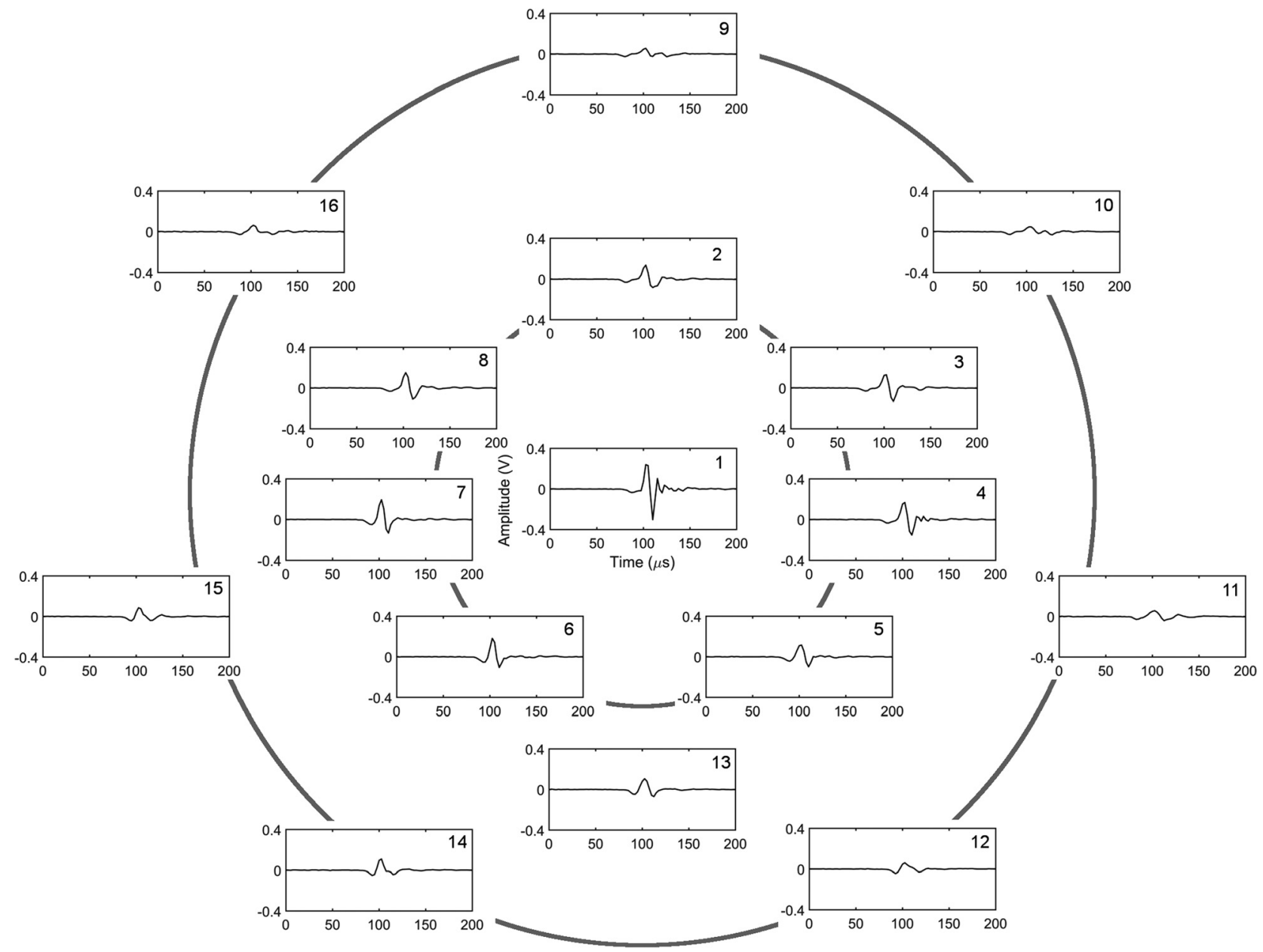

FIG. 3. Waveforms of a single click recorded on all hydrophones of the array as seen from the dolphin's perspective. Each waveform panel is numbered with the hydrophone location on which it was recorded. Note the panel locations are not to scale with the dimensions of the array.

level and centroid frequency [Figs. 6(A)-6(F)]; beam directivity increased with linearly with both parameters. However, there was no relationship between the beam aspect ratio (i.e., the ratio of the horizontal over the vertical beamwidths) to these parameters [Figs. $6(\mathrm{G})-6(\mathrm{H})]$.

There were 324 clicks where the center of the beam was directed at the central array hydrophone, allowing for comparison at consistent off-axis angles relative to the on-axis recordings (Table II). Within this subset of clicks, significant differences were found between azimuth groupings for all parameters $(p<0.001$, see methods section). Post hoc tests revealed that many significantly changed with increasing off-axis angular width from the beam center. The mean click duration ( $-10 \mathrm{~dB}$ energy duration) increased from $20.1 \mu$ s to 26.4 and $35 \mu$ s at $0^{\circ}, 9.7^{\circ}$, and $18.8^{\circ}$ off-axis, respectively [Fig. 7(A)]. Furthermore, the mean peak frequency, centroid frequency, rms bandwidth, and $-3 \mathrm{~dB}$ bandwidth all decreased significantly with increasing off-axis angle [Figs. $7(B)-7($ E) $]$. From $0^{\circ}$ to $18.8^{\circ}$ off-axis, these results correspond to a change of $-1 \mathrm{kHz} /$ degree in mean centroid frequency, $-1.2 \mathrm{kHz} /$ degree in mean peak frequency, -0.75 $\mathrm{kHz} /$ degree in mean $\mathrm{rms}$ bandwidth, and $-1.4 \mathrm{kHz} /$ degree in $-3 \mathrm{~dB}$ bandwidth. While the $-10 \mathrm{~dB}$ bandwidth decreased from the $0^{\circ}$ to $9.7^{\circ}$ beam locations, there was no further decrease from $9.7^{\circ}$ to $18.8^{\circ}$ [Fig. $\left.7(\mathrm{~F})\right]$.
The magnitude of the on-off axis parameter change was related to the beam directivity. Figure 8 shows the mean difference between the $0^{\circ}$ and $9.7^{\circ}$ azimuth recordings for individual clicks as a function of the click's directivity index. Clicks projected in a narrower beam (higher DI) generally showed a greater change in temporal and spectral parameters between the on-axis $\left(0^{\circ}\right)$ and $9.7^{\circ}$ off-axis recording locations. Off-axis measurements of centroid frequency and rms bandwidth showed the greatest dependence on beam directivity, while this relationship was less pronounced or insignificant for the duration, $-3 \mathrm{~dB}$ bandwidth, and $-10 \mathrm{~dB}$ bandwidth. The on-off axis change in peak frequency showed a bimodal pattern with modes at -4 and $-44 \mathrm{kHz}$. This bimodal pattern was related to the on-axis peak frequency [Fig. 8(C)] of the click signals. Higher frequency clicks with on-axis peak frequencies greater than $55 \mathrm{kHz}$ showed less change in peak frequency at the $9.7^{\circ}$ azimuths than clicks with peak frequencies below $55 \mathrm{kHz}$.

\section{DISCUSSION}

\section{A. On-axis click characteristics}

The broadband on-axis click characteristics from this captive spinner dolphin are generally in line with on-axis clicks from wild individuals (Schotten et al., 2004), yet 


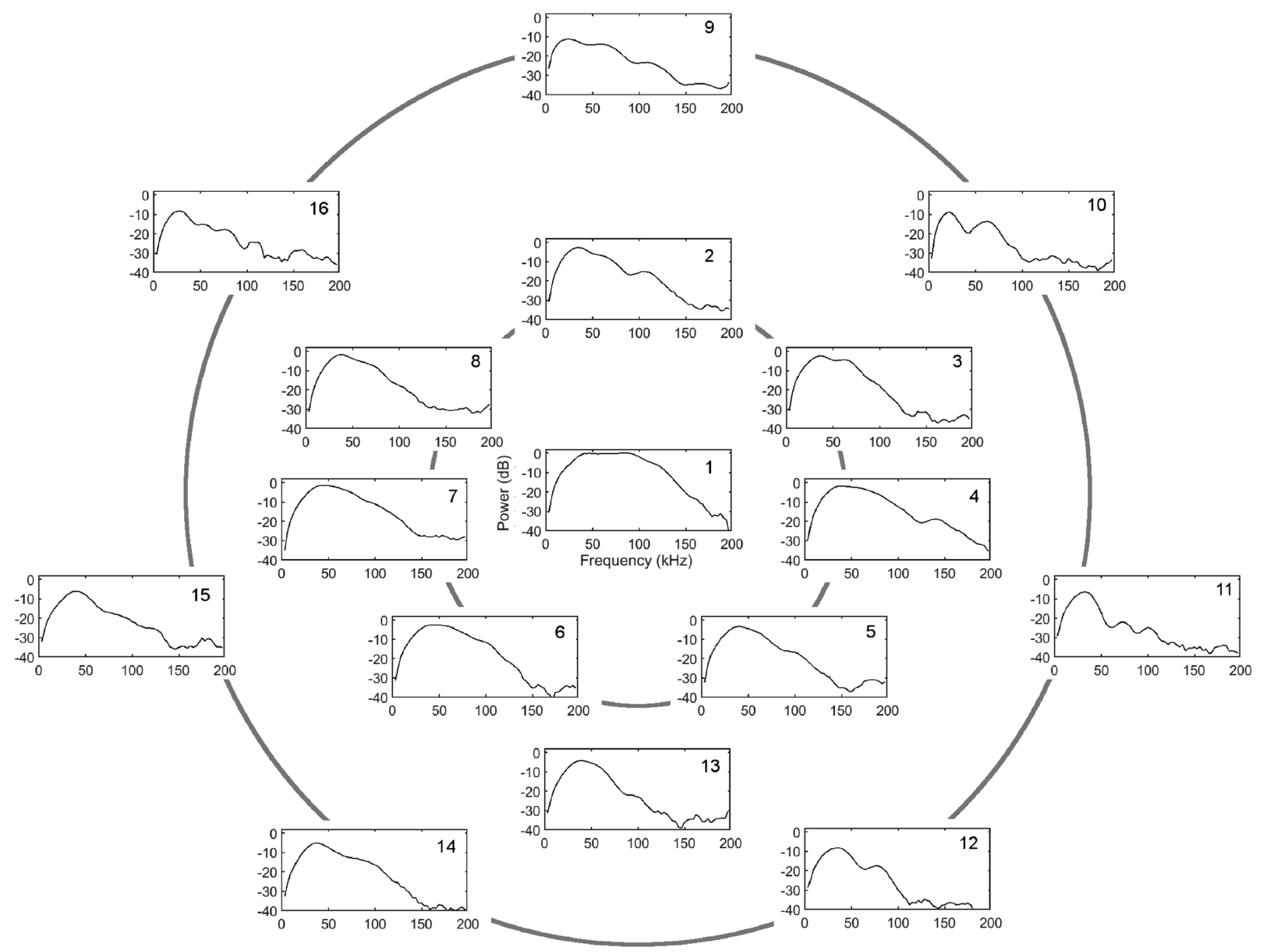

FIG. 4. Spectra of a single click recorded on all array hydrophones. Each spectrum is numbered with the hydrophone location on which it was recorded. Note the panel locations are not to scale with the dimensions of the array.

some differences are apparent (see Table I). The captive individual produced clicks that were lower in source level and frequency content than what has been described from recordings of wild individuals. This may be attributable to multiple factors or a combination thereof. First, the data presented here were collected from only a single individual of the species, and therefore likely reflect variability in click

TABLE I. Source properties of on-axis S. longirostris echolocation signals (mean \pm s.d.).

\begin{tabular}{lcc}
\hline \hline Parameters & This study & Schotten et al. (2004) \\
\hline$N$ & 1369 & $131-851$ \\
$\mathrm{SL}_{\mathrm{pp}}(\mathrm{dB}$ re: $1 \mu \mathrm{Pa})$ & $180 \pm 9.1(\max : 206)$ & $208 \pm 5$ \\
$\mathrm{SL}_{\text {rms }}(\mathrm{dB}$ re: $1 \mu \mathrm{Pa})$ & $170 \pm 9.3(\max : 198)$ & n.a. \\
$\mathrm{SL}_{\text {efd }}\left(\mathrm{dB}\right.$ re: $\left.1 \mu \mathrm{Pa}^{2} *_{\mathrm{s}}\right)$ & $123 \pm 8.3(\max : 150)$ & n.a. \\
Dur $_{-10 \mathrm{~dB}}(\mu \mathrm{s})$ & $20.1 \pm 4.8$ & $31 \pm 12$ \\
$f_{\mathrm{p}}(\mathrm{kHz})$ & $57.9 \pm 22.5$ & $69.7 \pm 23.1$ \\
$f_{0}(\mathrm{kHz})$ & $65.1 \pm 11.1$ & $80.4 \pm 12.1$ \\
$\mathrm{BW}_{\text {rms }}(\mathrm{kHz})$ & $29.3 \pm 5.7$ & $34.1 \pm 4.9$ \\
$\mathrm{BW}_{-3 \mathrm{~dB}}(\mathrm{kHz})$ & $54.4 \pm 19.5$ & $76.4 \pm 23.4$ \\
$\mathrm{BW}_{-10 \mathrm{~dB}}(\mathrm{kHz})$ & $107 \pm 28$ & n.a. \\
$Q$ & $2.3 \pm 0.5$ & n.a. \\
\hline \hline
\end{tabular}

production between individuals of the species to some degree (Houser et al., 1999). Additionally, odontocetes have been shown to alter click parameters depending on the echolocation task being performed (Au et al., 1985; Houser et al., 1999; Kloepper et al., 2012a; Philips et al., 2003), as well as the distance to an echolocation target (Au and Benoit-Bird, 2003; Wisniewska et al., 2012; Wisniewska et al., 2015). As the distance to a target is reduced, so are inter-click intervals (Schotten et al., 2004) and source levels (Au and BenoitBird, 2003). Odontocete click intervals can be as short as 1.5 to $3 \mathrm{~ms}$ (Lammers et al., 2004; Madsen et al., 2004; Verfuß et al., 2009), often observed during production of a terminal buzz in the final moments of prey capture when targets are close. Although no specific echolocation task was being performed in the current study, the generally short click intervals and low source levels suggest the dolphin may have often focused on closely ranged targets such as the hydrophone array or the various objects dropped in the water to elicit echolocation. This likely skewed the on-axis parameters reported here toward the lower spectral ranges of what the individual would normally produce. Furthermore, odontocetes have been shown to alter click source parameters as a result of changes in hearing capability (Kloepper et al., 

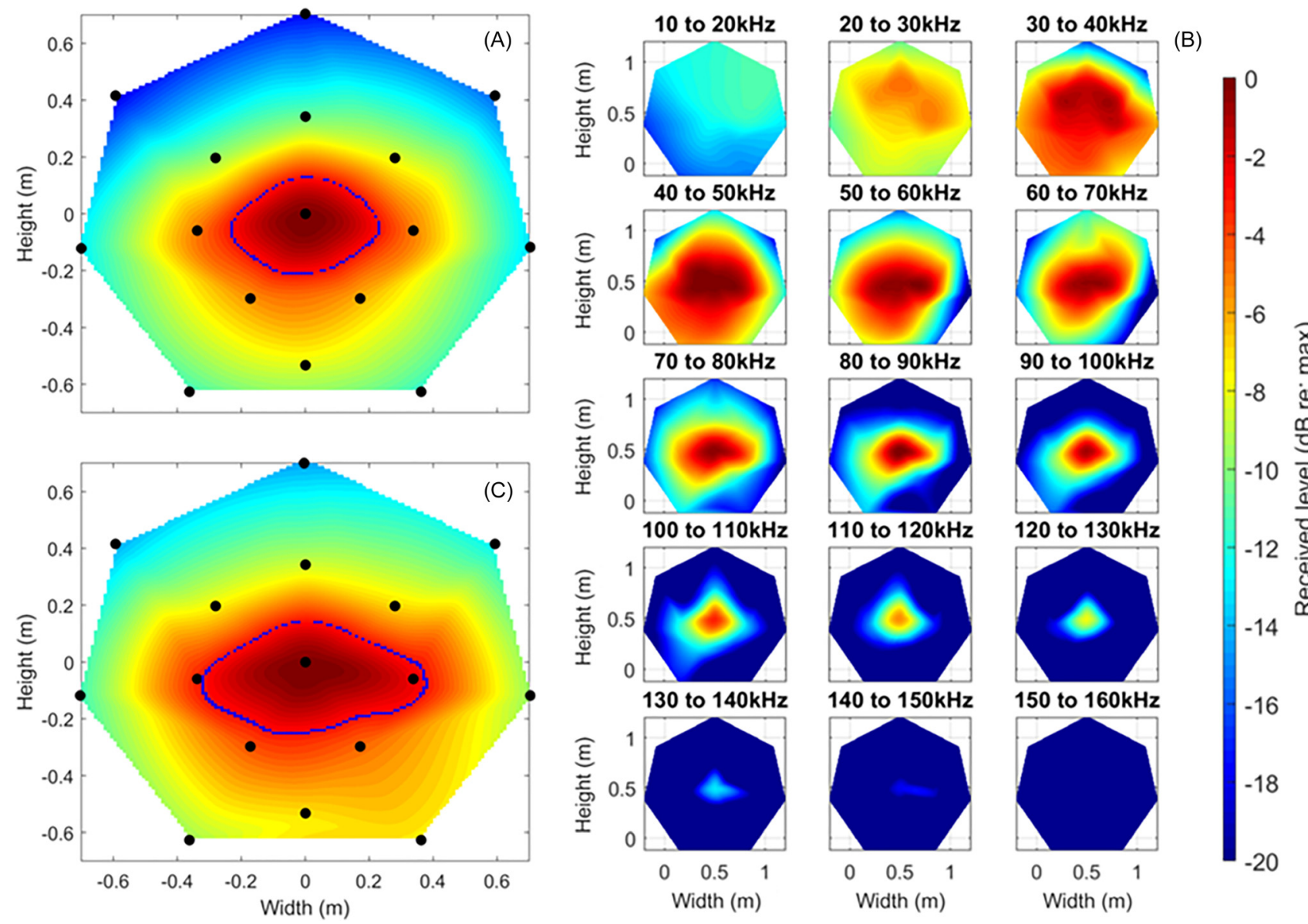

FIG. 5. (Color online) Beam shapes of three spinner dolphin echolocation clicks, as seen from the dolphin's perspective. Plots were interpolated using the pp received level of the clicks on each hydrophone (black dots). Small blue dots encircle the $-3 \mathrm{~dB}$ beam area. (A) Full spectrum beam shape of a click with vertical and horizontal angular beam widths of 9.4 and $14.3^{\circ}$, respectively (B) Frequency band-limited amplitude plot of a single echolocation click exhibiting a consistent single-lobed beam shape across all frequency bands. (C) Full spectrum beam shape of a click exhibiting significant vertical compression, with vertical width of $13.7^{\circ}$ and horizontal width of $24.0^{\circ}$.

2010). A previously published audiogram of this spinner dolphin indicates sensitive hearing up to approximately $90 \mathrm{kHz}$, but also suggests some degree of high frequency hearing loss possibly due to the effects of dynamite fishing (Pacini et al., 2016). If the spinner dolphin were to primarily produce clicks with centroid frequencies found in wild individuals $(70-90 \mathrm{kHz})$, a large fraction of the spectral energy in the outgoing clicks and returning echoes would fall within the supra-audal range of the animal's hearing. Instead, the mean click centroid frequency of $64 \mathrm{kHz}$ falls along the median of this animal's sensitive hearing range (see Pacini et al., 2016). It is therefore plausible that high frequency hearing loss may have influenced this individual's production of clicks with lower frequency content in response to a reduced range of sensitive hearing.

\section{B. Off-axis click characteristics}

The spinner dolphin clicks showed increased duration of the temporal waveform [Figs. 3, 7(A)] and a progressive loss of higher frequency energy as the off-axis angle increased [Figs. 4, 7(B), and 7(C)], the magnitude of which was influenced by beam directivity [Figs. $8(\mathrm{~B})-8(\mathrm{C})$ ]. This may be explained by complex reflection and propagation of the outgoing acoustic signal along the elements of the dolphin's transmission system. Cancelation of certain frequency components in a click results in a low-pass filter effect with a progressively lower cutoff frequency at the increasing offaxis locations (Beedholm and Mohl, 2006; Wahlberg et al., 2011b). This effect also explains the dependence of the onoff axis spectral change on beam directivity illustrated in Fig. $8(\mathrm{C})$, where the change in on-off axis peak frequency is dependent on both the beam directivity and the on-axis peak frequency. Signals with on-axis peak frequencies (and therefore a large portion of the distributed acoustic energy) below $52 \mathrm{kHz}$ are less influenced by the low pass filter effect at the $9.7^{\circ}$ off-axis azimuths.

Although beam directivity measurements have previously been reported for 16 odontocete species, only a few studies provide descriptions of off-axis click characteristics to varying degrees, complicating comparison between species. In general, the decrease in spectral emphasis and increased temporal distortion of off-axis clicks from this spinner dolphin are in line with results described for the bottlenose dolphin (Au et al., 2012), beluga (Au et al., 1987), false killer whale (Au et al., 1995), and Risso's dolphin (Madsen et al., 2004). One notable difference arises in the on-off axis change in rms bandwidth. Au et al. (2012) found 

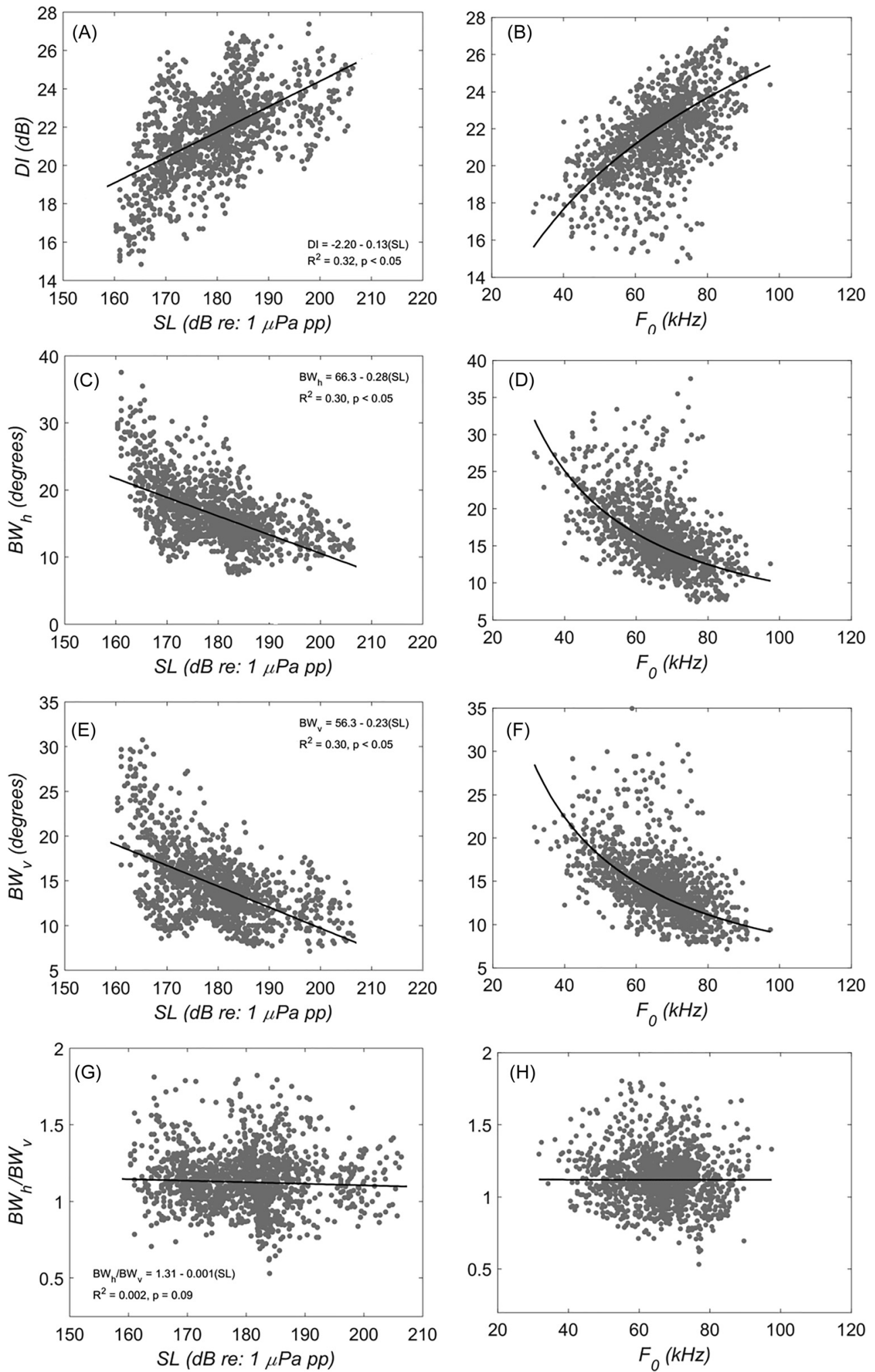

FIG. 6. Scatter plots comparing measurements of beam directivity (DI: directivity index; $\mathrm{BW}_{\mathrm{H}}$ : horizontal beam width; BW $\mathrm{V}_{\mathrm{V}}$ : vertical beam width) to click SL and centroid frequency $\left(f_{0}\right)$. Plots A, C, E, and G are fit with a linear regression. Lines in plots B, D, F, and H represent values modeled using a rectangular piston measuring $7.8 \times 8.6 \mathrm{~cm}(w \times h)$.

that rms bandwidth increased by approximately $12.5 \mathrm{kHz}$ at horizontal off-axis azimuths of $22.5^{\circ}$ in the bottlenose dolphin, whereas it was found to decrease at off-axis locations within $18.8^{\circ}$ in the spinner dolphin reported here and in examples within $10^{\circ}$ given for the Risso's dolphin (Madsen et al., 2004).
The characteristics of off-axis click signals have generally received less attention than on-axis descriptions in odontocetes, yet an improved understanding of how click parameters change across different areas of a transmission beam may be useful for improvements in species level classification of clicks recorded via passive acoustic monitoring 
TABLE II. Comparison of on- and off-axis characteristics of S. longirostris echolocation signals (mean \pm s.d.) where the transmission beam was centered on the hydrophone array.

\begin{tabular}{lccc}
\hline \hline & \multicolumn{3}{c}{ Beam angle } \\
\cline { 2 - 4 } Parameters & $0^{\circ}$ & $9.7^{\circ}$ & $18.8^{\circ}$ \\
\hline$N$ & 324 & 2268 & 2268 \\
$\operatorname{Dur}_{-10 \mathrm{~dB}}(\mu \mathrm{s})$ & $20.1 \pm 5$ & $26.4 \pm 8$ & $34.5 \pm 8$ \\
$f_{\mathrm{p}}(\mathrm{kHz})$ & $53.1 \pm 21$ & $41.7 \pm 13$ & $30.1 \pm 10$ \\
$f_{0}(\mathrm{kHz})$ & $65.7 \pm 11$ & $52.5 \pm 10$ & $46.8 \pm 11$ \\
$\mathrm{BW}_{\mathrm{RMS}}(\mathrm{kHz})$ & $72.3 \pm 11$ & $60.1 \pm 11$ & $58.2 \pm 14$ \\
$\mathrm{BW}_{-3 \mathrm{~dB}}(\mathrm{kHz})$ & $50.1 \pm 23$ & $35.7 \pm 17$ & $23.5 \pm 19$ \\
$\mathrm{BW}_{-10 \mathrm{~dB}}(\mathrm{kHz})$ & $108.6 \pm 27$ & $96.6 \pm 39$ & $95.2 \pm 54$ \\
\hline \hline
\end{tabular}

(PAM). When recording with PAM platforms, the orientation of the signaling animal is unknown, and resulting datasets likely include clicks recorded from both on-axis, and perhaps mainly off-axis, beam locations. Description and comparison of off-axis click dynamics between species may therefore be valuable for future efforts towards improving species-level classification.

Additionally, analysis of off-axis signals may also be valuable to better understand echolocation strategies employed by odontocetes. It has been shown that echolocating bats, and likely odontocetes, will orient their transmission beams so that a target is ensonified primarily by off-axis click signals at a specific azimuth, thereby creating an optimized click spectrum to maximize the available information on the target's bearing in the returning echo (Arditi et al., 2015; Kloepper et al., 2018; Yovel et al., 2010). Beam directivity changes in odontocetes have largely been discussed in the context of adapting the biosonar field of view according to a target's range, yet the resulting changes in off-axis spectral characteristics at specific azimuths around the beam may be an aspect of understanding odontocete echolocation strategies deserving of further study.

\section{Beam shape}

The use of two-dimensional arrays has previously revealed examples of dual-lobed beam shapes within certain frequency bands of echolocation clicks from the bottlenose dolphin (Tursiops truncatus, Starkhammar et al., 2011), false killer whale (Pseudorca crassidens, Kloepper et al., 2012b), and Risso's dolphin (Grampus griseus, Smith et al., 2016). However, the mechanism and potential function of the dual lobed shape is unknown. No dual lobed beams were observed from the spinner dolphin in the current study. Given the experimental differences between the studies, low individual sample sizes, and low occurrence rate of the dual lobed clicks in other odontocetes, it cannot be determined from the current data if this result is due to experimental, individual, or inter-specific differences.

While no dual lobes were observed, the spinner dolphin's beam was rotationally asymmetric around the beam axis, generally exhibiting a slight dorso-ventral, or vertical, compression. A few other odontocete species also exhibit transmission beams that are not rotationally symmetric, being either laterally compressed (false killer whale, Au et al., 1995) or vertically compressed (harbor porpoise, Koblitz et al., 2012). To what extent rotationally asymmetric beam characteristics may be functionally significant or simply a byproduct of the head anatomy is unknown. Odontocetes have been shown to manipulate the directivity of their beam during prey capture according to the distance to an echolocation target. It has been suggested that a vertically compressed beam may be functionally advantageous for species that forage in shallow water such as the harbor porpoise (Koblitz et al., 2012). In an animal swimming with the dorsal side oriented upwards, such rotational asymmetry could reduce reflections and reverberation from the sea surface or bottom while still maintaining an adequately large field of view. While the spinner dolphin often rests in shallow bays during the daytime, they forage offshore at night
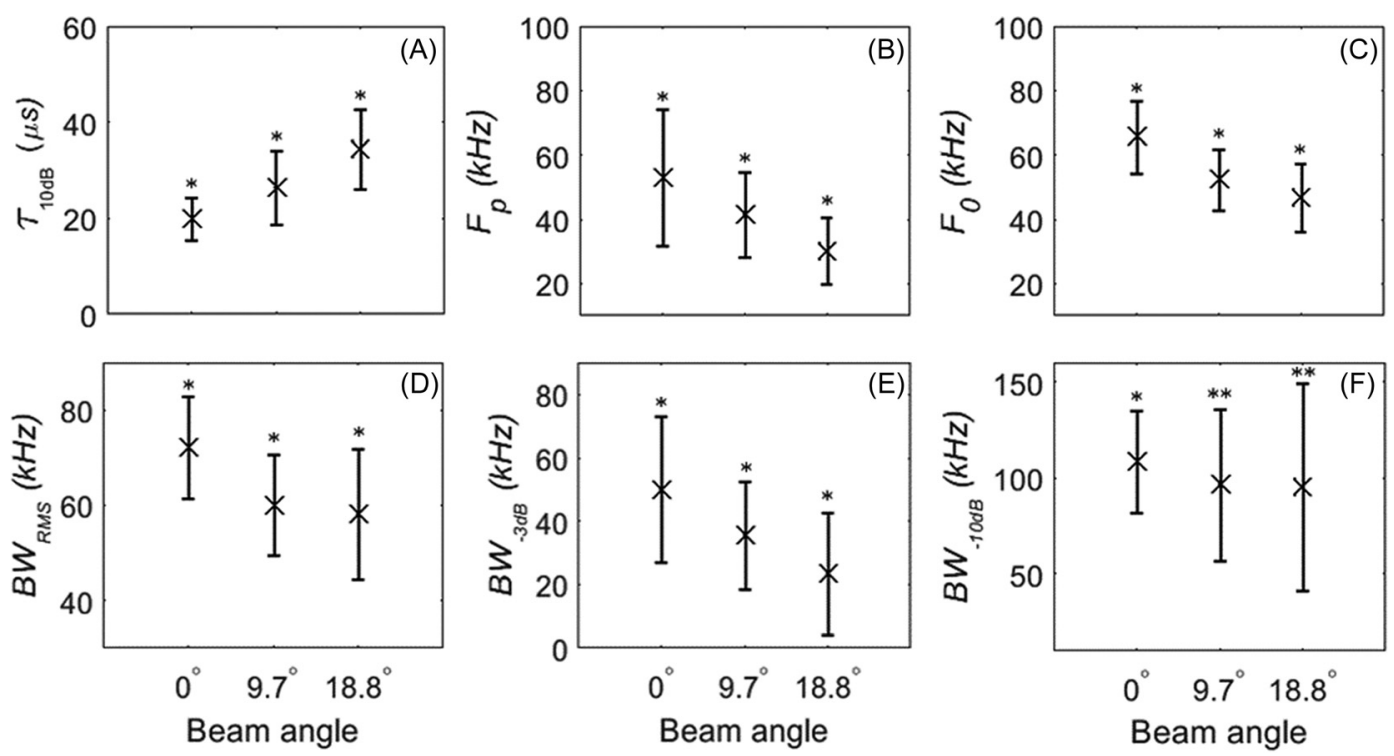

FIG. 7. Comparison plots of the mean \pm s.d. of echolocation parameters measured at $0^{\circ}$ (on-axis) and at $9.7^{\circ}$ and $18.8^{\circ}$ off-axis. For each individual plot, single asterisks $(*)$ denote statistically significant differences (alpha $<0.05)$ from two other groups, while double asterisks $(* *)$ denote statistically significant differences from one other group. 

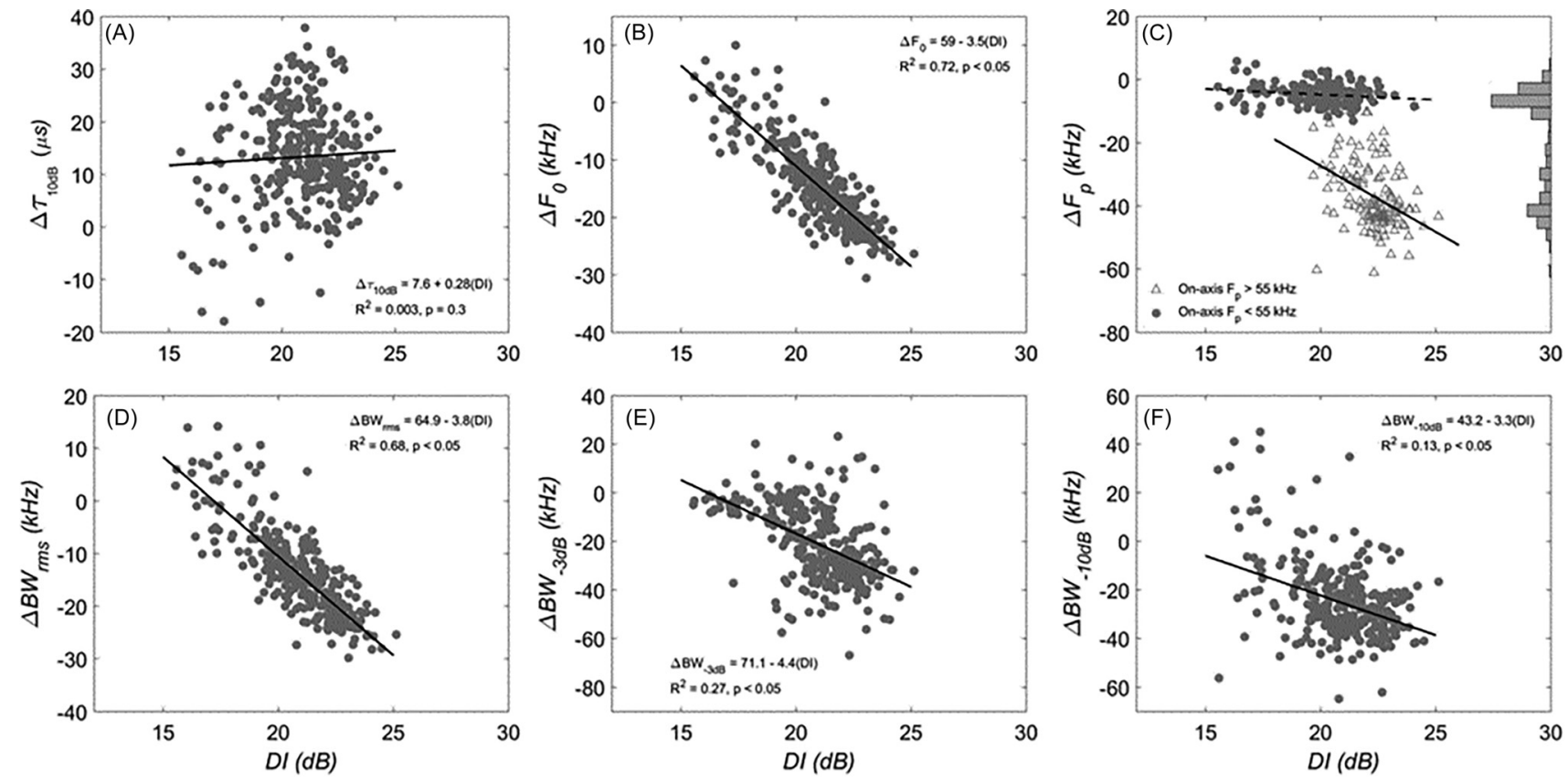

FIG. 8. Scatter plots comparing the mean difference in click measurements between the $0^{\circ}$ and $9.7^{\circ}$ azimuth recordings for individual clicks, plotted as a function of the click's directivity index.

(Lammers, 2004; Norris and Dohl, 1980), where bottom or surface reflections would be less consequential, and thus it seems less plausible that potential reduction from bottom or surface reflections would act as a driving force for the vertically compressed transmission beam in this species.

\section{Beam directivity}

A mean DI of $21.7 \mathrm{~dB}$ and angular beamwidths of $14.5^{\circ}$ $\left(\mathrm{BW}_{\mathrm{V}}\right)$ and $16.3^{\circ}\left(\mathrm{BW}_{\mathrm{H}}\right)$ makes the transmission beam of this spinner dolphin one of the broadest described for an odontocete to date. Mean directivity indices described or estimated for other odontocetes range between 18.3 for the Northern bottlenose whale (Hyperoodon ambullatus, Jensen et al., 2018; Wahlberg et al., 2011a) and $32.1 \mathrm{~dB}$ for the beluga (Delphapterus leucas, Au et al., 1987). Transmission beam directivity is proportional to the size of sound generating aperture (Urick, 1983), and thus it is not unexpected that the small spinner dolphin (head circumference $=59 \mathrm{~cm}$ at the blowhole) would have a broader transmission beam compared to what has been described in many other larger species. Yet odontocetes actively broaden their beams when echolocating on close targets or closing in on prey (Jensen et al., 2015; Ladegaard et al., 2017; Wisniewska et al., 2015), which coincide with decreases in inter-click-intervals, source levels, and spectral emphasis. Therefore, the mean beam measurements reported here may be biased by broader examples of what the dolphin is capable of producing and not representative of the species as a whole. The dolphin produced a small subset of clicks with centroid frequencies from 78 to $82 \mathrm{kHz}(n=93)$, which are similar to the mean value of $80.1 \mathrm{kHz}$ described from free-ranging individuals (Schotten et al., 2004). The mean DI of this click subset is $23.3 \mathrm{~dB}$, which may be a more appropriate general estimate for the species. In both echolocating bats and odontocetes, there is an overall similarity in measured beam directivity across species despite large differences in body size, which has led to the hypothesis that these animals have faced an evolutionary pressure to achieve a similarly high beam directivity (Jakobsen et al., 2012; Jensen et al., 2018; Koblitz et al., 2012). An estimated DI of $23.3 \mathrm{~dB}$ for the spinner dolphin here is more similar to other small-bodied odontocetes. Using these values, the scaling of click frequency content and DI with body mass for the spinner dolphin falls closely in line with what has recently been described for other odontocetes in general (Jensen et al., 2018) and is therefore in line with this hypothesis.

\section{CONCLUSION}

This study used a 16-element hydrophone array to record echolocation signals from a previously stranded and rehabilitated captive spinner dolphin. On-axis signals from the studied animal were generally lower in source level and frequency content that those reported for wild individuals of the species, which may be due to combination of multiple factors such as individual variability, experimental setup, and hearing loss. Signals recorded off the beam axis showed distortion and a reduced frequency emphasis compared to the on-axis signals, which is consistent with descriptions from other species. The spinner dolphin projected echolocation clicks in a rotationally asymmetric single-lobed beam. Although among the broadest described for an odontocete to date, this individual's beam is still highly directional and in line with the hypothesis that odontocetes have faced an evolutionary driving force to maintain high transmission beam directivity.

\section{ACKNOWLEDGMENTS}

The authors would like to thank the staff at Ocean Adventure for their time and assistance, Laura Kloepper for 
her assistance and advice on the data analysis, and Andy Solow for his help with the statistical analysis. The array system was originally designed by Stuart Ibsen. This work was funded by a research grant from the Sea World Busch Gardens Conservation Fund awarded to A.F.P. All work was conducted in compliance with University of Hawaii at Manoa IACUC and conducted under NMFS permit No. 16053 to P.E.N. This is contribution No. 1761 from the Hawaii Institute of Marine Biology.

Arditi, G., Weiss, A. J., and Yovel, Y. (2015). "Object localization using a biosonar beam: How opening your mouth improves localization," R. Soc. Open Sci. 2, 150225.

Au, W. W. L. (1993). The Sonar of Dolphins (Springer-Verlag, New York).

$\mathrm{Au}$, W. W. L., and Benoit-Bird, K. J. (2003). "Automatic gain control in the echolocation system of dolphins," Nature 423, 861-863.

Au, W. W. L., Branstetter, B. K., Moore, P. W., and Finneran, J. J. (2012). "The biosonar field around an Atlantic bottlenose dolphin (Tursiops truncatus)," J. Acoust. Soc. Am. 131, 569-576.

Au, W. W. L., Carder, D. A., Penner, R. H., and Scronce, B. L. (1985). "Demonstration of adaptation in beluga whale echolocation signals," J. Acoust. Soc. Am. 77, 726-730.

$\mathrm{Au}, \mathrm{W}$. W. L., and Hastings, M. C. (2008). Principles of Marine Bioacoustics (Springer US, New York).

Au, W. W. L., Pawloski, J. L., Nachtigall, P. E., Blonz, M., and Gisner, R. C. (1995). "Echolocation signal and transmission beam pattern of a false killer whale (Pseudorca crassidens)," J. Acoust. Soc. Am. 98, 51-59.

Au, W. W., Penner, R. H., and Turl, C. W. (1987). "Propagation of beluga echolocation signals," J. Acoust. Soc. Am. 82, 807-813.

Beedholm, K., and Mohl, B. (2006). "Directionality of sperm whale sonar clicks and its relation to piston radiation theory," J. Acoust. Soc. Am. 119, EL14.

Dolar, M. L. L., Walker, W. A., Kooyman, G. L., and Perrin, W. F. (2003). "Comparative feeding ecology of spinner dolphins (Stenella longirostris) and Fraser's dolphins (Lagenodelphis hosei) in the Sulu Sea," Mar. Mam. Sci. 19, 1-19.

Houser, D. S., Helweg, D. A., and Moore, P. W. (1999). "Classification of dolphin echolocation clicks by energy and frequency distributions," J. Acoust. Soc. Am. 106, 1579-1585.

Ibsen, S. D., Nachtigall, P. E., Krause-Nehring, J., Kloepper, L., Breese, M., Li, S., and Vlachos, S. (2012). "Spatial orientation of different frequencies within the echolocation beam of a Tursiops truncatus and Pseudorca crassidens," J. Acoust. Soc. Am. 132, 1213.

Jakobsen, L., Ratcliffe, J. M., and Surlykke, A. (2012). "Convergent acoustic field of view in echolocating bats," Nature 493, 93-96.

Jensen, F. H., Johnson, M., Ladegaard, M., Wisniewska, D. M., and Madsen, P. T. (2018). "Narrow acoustic field of view drives frequency scaling in toothed whale biosonar," Curr. Biol. 28, 3878.

Jensen, F. H., Rocco, A., Mansur, R. M., Smith, B. D., Janik, V. M., and Madsen, P. T. (2013). "Clicking in shallow rivers: Short-range echolocation of Irrawaddy and Ganges river dolphins in a shallow, acoustically complex habitat," PLoS One 8, e59284.

Jensen, F. H., Wahlberg, M., Beedholm, K., Johnson, M. P., Soto, N. A., and Madsen, P. T. (2015). "Single-click beam patterns suggest dynamic changes to the field of view of echolocating Atlantic spotted dolphins (Stenella frontalis) in the wild," J. Exp. Biol. 218, 1314-1324.

Kloepper, L. N., Buck, J. R., Liu, Y., and Nachtigall, P. E. (2018). "Off-axis targets maximize bearing Fisher Information in broadband active sonar," J. Acoust. Soc. Am. 143, EL43-EL48.

Kloepper, L. N., Nachtigall, P. E., and Breese, M. (2010). "Change in echolocation signals with hearing loss in a false killer whale (Pseudorca crassidens)," J. Acoust. Soc. Am. 128, 2233-2237.

Kloepper, L. N., Nachtigall, P. E., Donahue, M. J., and Breese, M. (2012a). "Active echolocation beam focusing in the false killer whale, Pseudorca crassidens," J. Exp. Biol. 215, 1306-1312.

Kloepper, L. N., Nachtigall, P. E., Quintos, C., and Vlachos, S. A. (2012b). "Single-lobed frequency-dependent beam shape in an echolocating false killer whale (Pseudorca crassidens)," J. Acoust. Soc. Am. 131, 577-581.
Koblitz, J. C., Wahlberg, M., Stilz, P., Madsen, P. T., Beedholm, K., and Schnitzler, H.-U. (2012). "Asymmetry and dynamics of a narrow sonar beam in an echolocating harbor porpoise," J. Acoust. Soc. Am. 131, 2315.

Ladegaard, M., Jensen, F. H., Beedholm, K., da Silva, V. M. F., and Madsen, P. T. (2017). "Amazon river dolphins (Inia geoffrensis) modify biosonar output level and directivity during prey interception in the wild," J. Exp. Biol. 220, 2654-2665.

Ladegaard, M., Jensen, F. H., de Freitas, M., Ferreira da Silva, V. M., and Madsen, P. T. (2015). "Amazon river dolphins (Inia geoffrensis) use a high-frequency short-range biosonar,” J. Exp. Biol. 218, 3091-3101.

Lammers, M. O. (2004). "Occurrence and behavior of Hawaiian spinner dolphins (Stenella longirostris) along Oahu's leeward and south shores," Aquat. Mam. 30, 237-250.

Lammers, M. O., Au, W. W. L., Aubauer, R., and Nachtigall, P. E. (2004). "A comparative analysis of the pulsed emissions of free-ranging Hawaiian spinner dolphins," in Echolocation in Bats Dolphins, edited by J. A. Thomas, C. F. Moss, and M. Vater (University of Chicago Press, Chicago, IL), pp. 414-419.

Madsen, P. T., Kerr, I., and Payne, R. (2004). "Echolocation clicks of two free-ranging, oceanic delphinids with different food preferences: False killer whales Pseudorca crassidens and Risso's dolphins Grampus griseus," J. Exp. Biol. 207, 1811-1823.

Manly, B. F. J. (2006). Randomization, Bootstrap, and Monte Carlo Methods in Biology (Chapman and Hall/CRC, New York).

Morisaka, T., and Connor, R. C. (2007). "Predation by killer whales (Orcinus orca) and the evolution of whistle loss and narrow-band high frequency clicks in odontocetes," J. Evol. Biol. 20, 1439-1458.

Norris, K. S., and Dohl, T. P. (1980). "Behavior of the Hawaiian spinner dolphin, Stenella longirostris," Fish. Bull. 77, 821-849.

Pacini, A. F., Nachtigall, P. E., Smith, A. B., Suarez, L. J. A., Magno, C., Laule, G. E., Aragones, L. V., and Braun, R. (2016). "Evidence of hearing loss due to dynamite fishing in two species of odontocetes," Proc. Mtgs. Acoust. 27, 010043

Perrin, W. F. (2009). "Spinner dolphin, Stenella longirostris," in The Encyclopedia of Marine Mammals, edited by W. F. Perrin, B. Wursig, and J. G. M. Thewissen (Academic Press, New York), pp. 1100-1103.

Philips, J. D., Nachtigall, P. E., Au, W. W. L., Pawloski, J. L., and Roitblat, H. L. (2003). "Echolocation in the Risso's dolphin, Grampus griseus," J. Acoust. Soc. Am. 113, 605-616.

Schotten, M., Au, W. W. L., Lammers, M. O., and Aubauer, R. (2004). "Echolocation recordings and localization of wild spinner dolphins (Stenella longirostris) and pantropical spotted dolphins (S attenuata) using a four hydrophone array," in Echolocation in Bats Dolphins, edited by J. A. Thomas, C. F. Moss, and M. Vater (University of Chicago Press, Chicago, IL), pp. 393-400.

Smith, A. B., Kloepper, L. N., Yang, W.-C., Huang, W.-H., Jen, I.-F., Rideout, B. P., and Nachtigall, P. E. (2016). "Transmission beam characteristics of a Risso's dolphin (Grampus griseus)," J. Acoust. Soc. Am. 139, 53-62.

Starkhammar, J., Moore, P. W., Talmadge, L., and Houser, D. S. (2011). "Frequency-dependent variation in the two-dimensional beam pattern of an echolocating dolphin," Biol. Lett. 7, 836-839.

Urick, R. J. (1983). Principles of Underwater Sound (Tata McGraw-Hill Education, New York).

Verfuß, U. K., Miller, L. A., Pilz, P. K., and Schnitzler, H.-U. (2009). "Echolocation by two foraging harbour porpoises (Phocoena phocoena)," J. Exp. Biol. 212, 823-834.

Wahlberg, M., Beedholm, K., Heerfordt, A., and Møhl, B. (2011a). "Characteristics of biosonar signals from the northern bottlenose whale, Hyperoodon ampullatus," J. Acoust. Soc. Am. 130, 3077-3084.

Wahlberg, M., Jensen, F. H., Aguilar Soto, N., Beedholm, K., Bejder, L., Oliveira, C., Rasmussen, M., Simon, M., Villadsgaard, A., and Madsen, P. T. (2011b). "Source parameters of echolocation clicks from wild bottlenose dolphins (Tursiops aduncus and Tursiops truncatus)," J. Acoust. Soc. Am. 130, 2263.

Wisniewska, D. M., Johnson, M., Beedholm, K., Wahlberg, M., and Madsen, P. T. (2012). "Acoustic gaze adjustments during active target selection in echolocating porpoises," J. Exp. Biol. 215, 4358-4373.

Wisniewska, D. M., Ratcliffe, J. M., Beedholm, K., Christensen, C. B., Johnson, M., Koblitz, J. C., Wahlberg, M., and Madsen, P. T. (2015). "Range-dependent flexibility in the acoustic field of view of echolocating porpoises (Phocoena phocoena)," Elife 4, e05651.

Yovel, Y., Falk, B., Moss, C. F., and Ulanovsky, N. (2010). "Optimal localization by pointing off axis," Science 327, 701-704. 